\title{
A novel thermally evaporated etching mask for low- damage dry etching
}

DOI:

10.1109/TNANO.2017.2662218

\section{Document Version}

Accepted author manuscript

Link to publication record in Manchester Research Explorer

\section{Citation for published version (APA):}

Wang, Y., Zhu, G., Wang, Q., Qian Xin, Han, L., \& Song, A. (2017). A novel thermally evaporated etching mask for low-damage dry etching. IEEE Transactions on Nanotechnology, 16(2), 290.

https://doi.org/10.1109/TNANO.2017.2662218

\section{Published in:}

IEEE Transactions on Nanotechnology

\section{Citing this paper}

Please note that where the full-text provided on Manchester Research Explorer is the Author Accepted Manuscript or Proof version this may differ from the final Published version. If citing, it is advised that you check and use the publisher's definitive version.

\section{General rights}

Copyright and moral rights for the publications made accessible in the Research Explorer are retained by the authors and/or other copyright owners and it is a condition of accessing publications that users recognise and abide by the legal requirements associated with these rights.

\section{Takedown policy}

If you believe that this document breaches copyright please refer to the University of Manchester's Takedown Procedures [http://man.ac.uk/04Y6Bo] or contact uml.scholarlycommunications@manchester.ac.uk providing relevant details, so we can investigate your claim.

\section{OPEN ACCESS}




\title{
A novel thermally evaporated etching mask for low-damage dry etching
}

\author{
Hanbin Wang, Yiming Wang, Gengchang Zhu, Qingpu Wang, Qian Xin, Lin Han, and Aimin Song, Senior \\ Member, IEEE
}

\begin{abstract}
Dry etching is widely used for nanofabrication and it requires reliable etching masks. However, hard dry etching masks usually need high-temperature and/or plasma deposition, which may causes damage to temperature-sensitive materials and semiconductor surface. Here, we develop a novel etching mask material, silicon monoxide ( $\mathrm{SiO})$, which is thermally evaporated and hence can avoid such drawbacks. The etching selectivity of evaporated $\mathrm{SiO}$ is shown to be higher than 50:1, comparable to sputtered $\mathrm{SiO}_{2}$. A nanochannel device, called self-switching diode (SSD), is fabricated to evaluate the mask-deposition-process damage because of its high sensitivity to the process damage. In comparison to commonly used sputtered $\mathrm{SiO}_{2}$ and polymethyl methacrylate (PMMA) mask, the SSD fabricated using evaporated $\mathrm{SiO}$ exhibit the highest channel conductance, strongest nonlinearity, and best high-frequency performance. Hall measurements also reveal that the carrier mobility of nanochannels etched with $\mathrm{SiO}$ mask is twice that of similar channels with $\mathrm{SiO}_{2}$ mask.
\end{abstract}

Index Terms-Silicon monoxide, Dry etching, Etching mask, Nanoscale device, Self-switching diode

\section{INTRODUCTION}

$\mathrm{W}$ ith the rapid scaling of semiconductor devices, device channels have become nanometer scaled wires, fins or column $[1,2,3]$. Dry etching or reactive-ion etching is essential to define these nanochannels via top-down techniques. However, dry etching of nanoscale channels on sensitive materials, like III-V, oxide and organic semiconductors, are still challenging due to the restriction of etching mask. Photoresists and electron-beam resists are commonly used as dry etching mask because of their process feasibility. However, these organic resists have low etching resistance and are not suitable for nanoscale structures with high aspect ratio. The thickness of resists has to be reduced to guarantee the small line width in lithography, which makes organic masks not capable of protecting the semiconductors beneath them during dry

This work has been supported by the Engineering and Physical Sciences Research Council (EPSRC) (Grant Nos. EP/G03737X/1 and EP/N021258/1), National Basic Research Program of China (Grant No. 2016YFA0301200), and National Natural Science Foundation of China (Grant Nos. 11374185 and 11304180).

Hanbin Wang, Yiming Wang, Gengchang Zhu, Qingpu Wang, Qian Xin, Lin Han, and Aimin Song are with the Center of Nanoelectronics and School of Microelectronics, Shandong University, Jinan 250100, China (e-mail: sduwhb@gmail.com; wym@sdu.edu.cn; zhugengchang@yeah.net; wangqingpu@sdu.edu.cn; xinq@sdu.edu.cn; hanlin@sdu.edu.cn; a.song@manchester.ac.uk).

Aimin Song is also with the School of Electrical and Electronics Engineering, University of Manchester, Manchester M13 9PL, U.K. etching process [4]. Although some electron-beam resists, such as hydrogen silsesquioxane (HSQ) could be used as hard mask and show superior dry etching resistance [5], the high cost and poor storage stability impede its pervasive application. Metal masks have already been widely used in the fabrication of micro-electro-mechanical systems (MEMS) or waveguides [6-8]. However, they are not suitable for all device etching, because the afterwards removal may etch or oxidize some semiconductors. Inorganic dielectric masks are more commonly used for nanochannels' dry etching. Many inorganic dielectric materials, such as $\mathrm{SiO}_{2}, \mathrm{SiN}_{\mathrm{x}}$ and $\mathrm{Al}_{2} \mathrm{O}_{3}$, have been extensively studied and widely used [9-11]. However, they usually need plasma and/or high-temperature deposition, like sputtering, plasma-enhanced chemical vapor deposition (PECVD) or atomic layer deposition (ALD), which have non-negligible effect on sensitive materials. The plasma deposition has been found to cause severe damage to the surface of semiconductors and deteriorate the performance of devices, especially those with active layer close to surface [12-15]. High-temperature deposition may cause temperature-sensitive materials, for instance oxide semiconductors or organics, degenerate or deform. Furthermore, the flammable or toxic reaction gases in ALD make the deposition process very dangerous.

Here, we introduce a novel dry etching mask material- silicon monoxide ( $\mathrm{SiO}$ ) for the fabrication of nanochannels on sensitive semiconductors. $\mathrm{SiO}$ has been used as dielectric layer in MOSFET, protection layer on Graphene and anode materials in Li-iron battery. The $\mathrm{SiO}$ mask can be deposited by thermal evaporation while keep the substrate at room-temperature. This process not only avoids inducing damage to the surface of semiconductors, but also is feasible to organic substrates. In this work, detailed characteristics of $\mathrm{SiO}$ mask have been performed in comparison with the commonly used polymethyl methacrylate (PMMA) and $\mathrm{SiO}_{2}$ masks. In order to evaluate the possible damage to host material during deposition process, a nanochannel device- self-switching diode (SSD) was fabricated because of its high sensitivity to any process damage [16-18]. SSD is a novel unipolar device and has amount of advantages including broadband, zero threshold, low noise, and ease of integration, etc. The direct current (DC) and high-frequency performances of the SSDs fabricated with different etching mask materials are compared in this study, and the possible physical mechanisms are analyzed with the assistance of Hall measurements. 


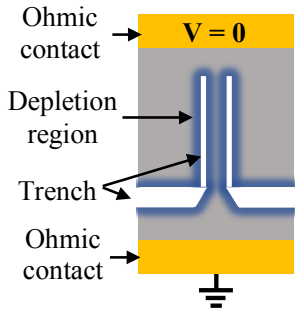

(a)

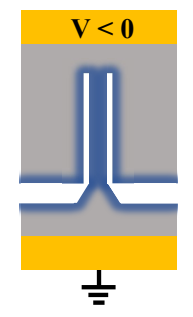

(b)

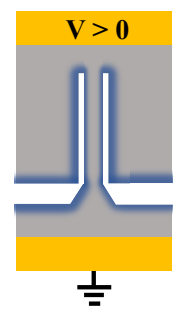

(c)
Fig. 1. Schematic illustration of SSD. (a) At zero bias, the nanochannel is partially depleted due to the surface states. (b) At bias $V<0$, the nanochannel is fully depleted as the electrostatic field effect increases the width of depletion region inside the channel. (c) At bias $V>0$, the nanochannel is opened because the electrostatic field reduces the depletion region.

\section{EXPERIMENTAL PROCEDURE}

\section{A. Preparation of $\mathrm{SiO}$ mask}

High purity (99.95\%) $\mathrm{SiO}$ powder was put in the tungsten boat which was connected to the electrodes in the vacuum chamber of HHV Auto 306 thermal evaporator. The chamber pressure was then evacuated to $2 \times 10^{-6}$ Torr and kept below $1 \times 10^{-5}$ Torr during the evaporation to prevent the $\mathrm{SiO}$ film from residual gas contaminating. The deposition rate was $1 \AA / \mathrm{s}$ and the final thickness was $50 \mathrm{~nm}$. Patterns of $\mathrm{SiO}$ mask was transferred through exposed PMMA E-beam resist using an Oxford Pro 100 ICP-RIE system. And the etching recipe of $\mathrm{SiO}$ was the same as that of $\mathrm{SiO}_{2}$. The etchant gases were $\mathrm{CHF}_{3}$ and Ar with the flow ratio of 1:4. The etching pressure was 5 mTorr. The ICP power was $300 \mathrm{~W}$ to generate stable and repeatable plasma, and the RF power was $5 \mathrm{~W}$ to minimize the plasma damage to the underneath InGaAs layer.

\section{B. Fabrication of InGaAs SSDs}

SSDs were fabricated to investigate the effects of thermally evaporated $\mathrm{SiO}$ mask on the properties of nanoscale devices. The SSD is a unipolar two-terminal device. It consists of two insulating L-shaped trenches opposite to each other, creating a semiconductor nanochannel between them as shown in Fig.1. At zero bias, the nanochannel is close to pinch-off by the surface states as illustrated in Fig. 1(a). A negative bias $(V<0)$ further depletes the channel and results in a zero or low current, whereas a positive bias $(V>0)$ counteracts the lateral depletion and widens the effective width of the channel to enable a large current to flow. This results in a diode-like nonlinear currentvoltage $(I-V)$ characteristic.

The substrate of SSDs was epitaxial InGaAs grown on InP substrate and, from bottom to top, includes a $300 \mathrm{~nm}$ InAlAs buffer layer, a $15 \mathrm{~nm}$ InGaAs channel layer, a $15 \mathrm{~nm}$ InAlAs barrier layer and a $10 \mathrm{~nm}$ InGaAs cap layer. A sheet dopant of silicon with the density of $6 \times 10^{18} \mathrm{~cm}^{-2}$ was introduced $5 \mathrm{~nm}$ deep in the cap layer. The carrier density and electron mobility of the channel layer, calculated by Hall measurements at room temperature, were $1.87 \times 10^{12} \mathrm{~cm}^{-2}$ and $1.01 \times 10^{4} \mathrm{~cm}^{2} / \mathrm{Vs}$ respectively. Fabrication of devices started with insulating 20- $\mu$ m-wide mesa by $\mathrm{H}_{3} \mathrm{PO}_{4} / \mathrm{H}_{2} \mathrm{O}_{2} / \mathrm{H}_{2} \mathrm{O}$-based wet etching.

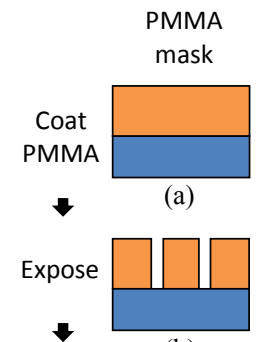

(b)

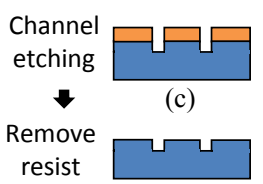

(d)

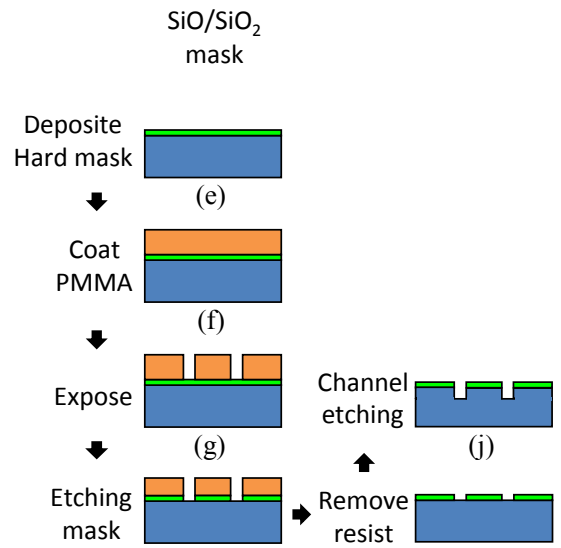

(h)
Fig. 2. Schematic illustration of SSDs channel fabrication processes with different masks. (a) - (d) are with PMMA mask. (e) - (j) are with $\mathrm{SiO}$ or $\mathrm{SiO}_{2}$ mask. (a) Spin coat $450 \mathrm{~nm}$ PMMA. (b) Expose and develop PMMA. (c) Dry etch InGaAs channel, the thickness of PMMA also reduced during etching. (d) Remove PMMA residue with oxygen plasma. (e) Deposit SiO or $\mathrm{SiO}_{2}$ film. (f) Spin coat $230 \mathrm{~nm}$ PMMA. (g) Expose and develop PMMA. (h) Dry etch $\mathrm{SiO}$ or $\mathrm{SiO}_{2}$ film with PMMA as mask. (i) Remove PMMA with oxygen plasma. (j) Dry etch InGaAs channel.

Then, $\mathrm{Au} / \mathrm{Ge} / \mathrm{Au} / \mathrm{Ni} / \mathrm{Ti} / \mathrm{Au}$ was evaporated successively followed by a $400{ }^{\circ} \mathrm{C}$ RTA process at $\mathrm{N}_{2}$ atmosphere to form ohmic contacts.

The following SSD channel etching was the most important process. Different etching procedures were used for three different masks: spin coated PMMA, thermally evaporated $\mathrm{SiO}$ and RF sputtered $\mathrm{SiO}_{2}$. Fig. 2 depicts a schematic illustration of channel fabrication processes. For the devices with PMMA mask, a 450-nm-thick PMMA layer was spin coated. After being exposed by Raith E-line plus E-beam exposure machine and developed in a mixture of MIBK and IPA with the ratio of $1: 3$, the PMMA mask was hard baked at $110^{\circ} \mathrm{C}$ for 30 mins in oven to increase its etching resistance. Whereas, for the devices with $\mathrm{SiO}$ or $\mathrm{SiO}_{2}$ etching mask, 50-nm-thick mask was deposited onto substrate, firstly. Then 230-nm-thick PMMA was spin coated. Patterns on $\mathrm{SiO}$ or $\mathrm{SiO}_{2}$ were transferred from the exposed PMMA resist by dry etching using the $\mathrm{SiO}_{2}$ etching recipe as mentioned before. The etching rate of $\mathrm{SiO}$ and $\mathrm{SiO}_{2}$ was $13 \mathrm{~nm} / \mathrm{min}$ and the selectivity of PMMA to silox was 2:1. Oxygen plasma ashing was executed to remove the PMMA resist and the generated polymer. Finally dry etching was performed to produce the trenches of all three devices. The etchant gases were $\mathrm{CH}_{4}, \mathrm{H}_{2}$ and $\mathrm{Ar}$ at the flow rates of 10, 30 and $10 \mathrm{sccm}$, respectively. The ICP power was $300 \mathrm{~W}$ to produce high-density plasma and the RF power was $5 \mathrm{~W}$ to minimize the etching damage. The etching rate of InGaAs was $14 \mathrm{~nm} / \mathrm{min}$, and the depth of etched trenches was about $100 \mathrm{~nm}$. In all the dry etching processes as mentioned above, the absolute value of the bias voltages were kept below $110 \mathrm{~V}$ to minimize the bombardment of plasma to substrates. 


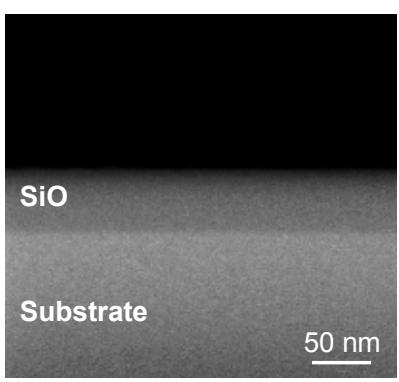

(a)

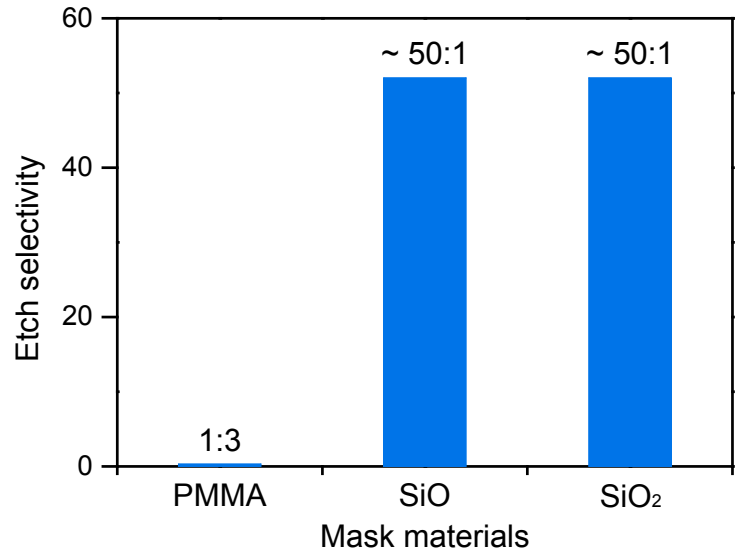

(c)

Fig. 3. (a) SEM image of the thermally evaporated SiO film. (b) SEM image of the RF sputtered $\mathrm{SiO}_{2}$ film. (c) Etch selectivity of different mask materials to InGaAs.

\section{RESUlts AND Discussion}

\section{A. Prosperities of thermally evaporated $\mathrm{SiO}$}

In Fig. 3(a), the Scanning Electron Microscope (SEM) image of 50 -nm-thick thermally evaporated $\mathrm{SiO}$ shows comparable uniformity as that of RF sputtered $\mathrm{SiO}_{2}$ thin films on silicon substrates, as shown in Fig. 3(b). The crystal size of SiO film, as reported by Klaus [19], is no larger than $2 \mathrm{~nm}$. The small grain size of $\mathrm{SiO}$ film is very favorable to nanofabrication.

To compare the dry etching resistance of $\mathrm{SiO}$ mask to traditional masks, E-beam resist $\mathrm{PMMA}, \mathrm{SiO}_{2}$ and $\mathrm{SiO}$ were dry etched simultaneously with the same InGaAs SSD trench etching condition. The etching selectivity, defined as the ratio of InGaAs etch rate to that of masks, are showed in Fig. 3(c). The results show that PMMA has a low etching selectivity ratio of 1:3, whereas both evaporated $\mathrm{SiO}$ and sputtered $\mathrm{SiO}_{2}$ have a much higher selectivity ratio of over 50 .

\section{B. Different masks on the properties of SSDs}

The morphology of InGaAs SSDs dry etched with PMMA, $\mathrm{SiO}_{2}$ and $\mathrm{SiO}$ masks were compared, as shown in Fig. 4. The designed width of SSD channels and trenches were $125 \mathrm{~nm}$ and $40 \mathrm{~nm}$, respectively. The channel length was $1 \mu \mathrm{m}$. In Fig. 4(a), the SSD channels are crooked and the edges of channels are rough. These may due to the softening and erosion of PMMA mask during dry etching. As measured by SEM, the thickness of remained PMMA mask after etching is only $1 / 3$ of the initial

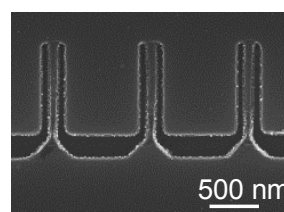

(a)

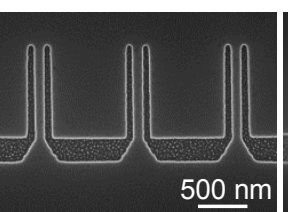

(b)

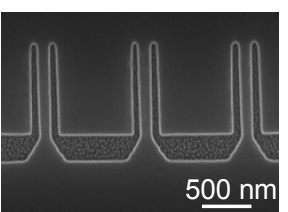

(c)
Fig. 4. SSDs dry etched with different masks. (a) SEM images of SSDs etched with $450 \mathrm{~nm}$ PMMA mask. SSD channels are bend because PMMA mask was softened during the etching. (b) SSDs etched with $\mathrm{SiO}_{2}$ mask. (c) SSDs etched with $\mathrm{SiO}$ mask.

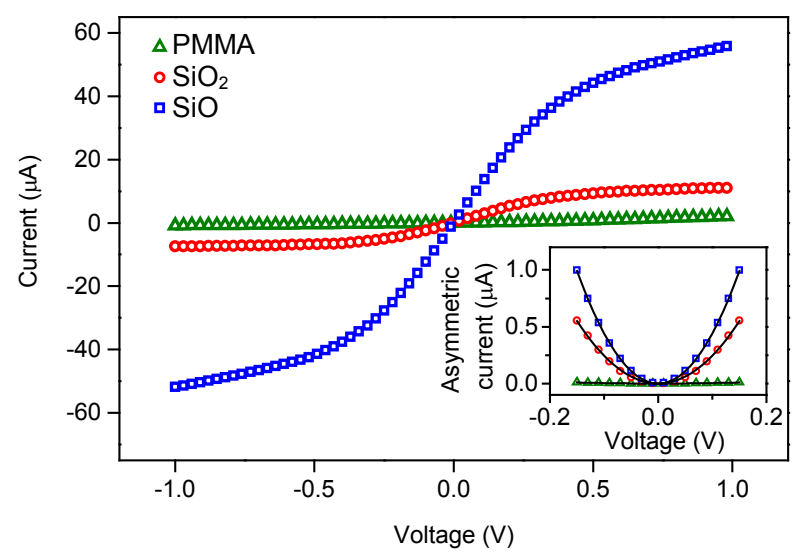

Fig. 5. Measured $I-V$ characteristics of SSD with $\mathrm{PMMA}, \mathrm{SiO}_{2}$ and $\mathrm{SiO}$ mask. The inset figure is the extracted (symbols) and fitted (line) asymmetric component of the $I-V$ curves.

TABLE I

EXTRACTED PARAMETERS FORM IV CURVES

\begin{tabular}{lccc}
\hline \hline $\begin{array}{c}\text { Parameters at } \\
\text { zero bias }\end{array}$ & $\begin{array}{c}\text { PMMA } \\
\text { mask }\end{array}$ & $\mathrm{SiO}_{2}$ mask & SiO mask \\
\hline$R_{0}(\mathrm{k} \Omega)$ & 977 & 37.1 & 7.88 \\
$G_{d}(\mu \mathrm{S})$ & 1.11 & 28.0 & 78.4 \\
$G_{d}^{\prime}\left(\mu \mathrm{A}^{2} / \mathrm{V}\right)$ & 0.78 & 49.0 & 88.2 \\
\hline \hline \multicolumn{1}{c}{$R_{0}, G_{d}$ and $G_{d}^{\prime}$ are resistance, differential conductance and } & corectively.
\end{tabular}

value. Besides the thickness, the geometric shape of PMMA mask was also changed during the dry etching as a result of ion bombardment and plasma heating effect, which is commonly observed in dry etching process with organic resists because of their poor etching resistance and low soften temperature [20]. As a contrast, the SSDs etched with $\mathrm{SiO}_{2}$ and $\mathrm{SiO}$ hard masks show very good morphology. The channels are straight and the edges of trenches are smooth.

DC electrical characteristics of the SSDs with different etching masks were measured separately, as shown in Fig. 5. The inset figure in Fig. 5 shows the asymmetric current (I $I_{\text {asymmetric }}$ ) of SSDs extracted from the $I-V$ curves using the following equation: $I_{\text {asymmetric }}=[I(-V)+I(V)] / 2$, where $I(-V)$ and $I(V)$ are the current of devices under backward and forward bias, respectively. The symbols in the figure are experimental results and the solid lines are fitted quadric curves. The good matching of measured results with fitting curves confirms that all SSDs work in triode-region mode [21]. The extracted zero voltage differential conductance $G_{d}=\left.\frac{\mathrm{d} I}{\mathrm{~d} V}\right|_{V=0}$ 
and curvature $G_{d}^{\prime}=\left.\frac{\mathrm{d}^{2} I}{\mathrm{~d} V^{2}}\right|_{V=0}$, where $V$ is the applied DC bias and $I$ is the current from $I-V$ curves [22], are listed in Table I. Both $G_{d}$ and $G^{\prime}{ }_{d}$ of the SSD with PMMA as mask are much lower than the devices with hard masks. This is caused by the damage of channels during dry etching because of PMMA mask's poor etching resistance.

As a novel ultrahigh frequency diode, SSD is a very promising candidate for $\mathrm{THz}$ detector. The responsivity of $\mathrm{RF}$ detectors, which is defined as the ratio of output DC voltage over input signal power, is a key parameter to evaluate its detecting ability. Fig. 6(a) shows the zero bias responsivity of SSDs with signal frequency ranged from $10 \mathrm{GHz}$ to $220 \mathrm{GHz}$ at room temperature. Both the SSDs fabricated with PMMA and $\mathrm{SiO}_{2}$ masks present obvious decrease in responsivity to the increasing frequency. Whereas the SSD with $\mathrm{SiO}$ mask shows constant responsivity through the full frequency range. This result indicates that the thermally evaporated $\mathrm{SiO}$ etching mask benefits the high frequency performance of SSDs.

Apart from responsivity, noise-equivalent-power (NEP) is another key factor in evaluating RF detectors. Fig. 6(b) shows the thermal NEP of SSDs with different masks calculated from the equation: NEP $=\frac{\sqrt{4 k T R_{0}}}{\eta}$, where $k$ is the Boltzmann's constant, $T$ is the absolute temperature, $R_{0}$ is the zero-bias resistance as listed in Table I, and $\eta$ is the measured responsivity in Fig. 6(a). Compared to the SSDs with PMMA or $\mathrm{SiO}_{2}$ mask, the SSD with $\mathrm{SiO}$ mask show much smaller NEP, especially at high frequency of $220 \mathrm{GHz}$. The maximum NEP of the SSD with $\mathrm{SiO}$ mask was about $400 \mathrm{pW} / \mathrm{Hz}^{1 / 2}$, which is 1-2 orders of magnitude smaller than those of the other two. This was contributed by the higher responsivity of the SSD with $\mathrm{SiO}$ mask at high frequency and smaller resistance at zero bias. The NEP of the SiO masked 3-channel parallelized SSD was a little higher than that of commercial Schottky diode, which usually is less than $50 \mathrm{pW} / \mathrm{Hz}^{1 / 2}$. However, this will not limit the application of SSD detectors, because the final NEP value is reasonably low due to their easy integration in parallel $[23,24]$.

\section{Hall bar fabricated with $\mathrm{SiO}$ and $\mathrm{SiO}_{2}$ masks}

To explain the reasons for better high frequency performance of the SSD with $\mathrm{SiO}$ mask compared to that with traditional $\mathrm{SiO}_{2}$ mask, nanoscale Hall bars were fabricated with $\mathrm{SiO}_{2}$ and $\mathrm{SiO}$ masks using the same substrate and process conditions for SSDs. Fig. 7 shows SEM image of the fabricated Hall bar. The width of hall bars were ranged from $100 \mathrm{~nm}$ to $200 \mathrm{~nm}$ and the etching depth was $100 \mathrm{~nm}$.

Measured carrier density $(n)$ and hall mobility $(\mu)$ at room temperature are listed in Table II. Both the carrier density and mobility of hall bars fabricated with $\mathrm{SiO}_{2}$ mask are smaller than those with $\mathrm{SiO}$ mask. The mobility of the former is only half of the latter. This is due to the plasma damage caused during the sputtering-deposition process of $\mathrm{SiO}_{2}$. Katsushiko et al. pointed out that the ion bombardment from $\mathrm{SiO}_{2}$ deposition could induce damage to substrates [25]. Tsubaki et al. reported that

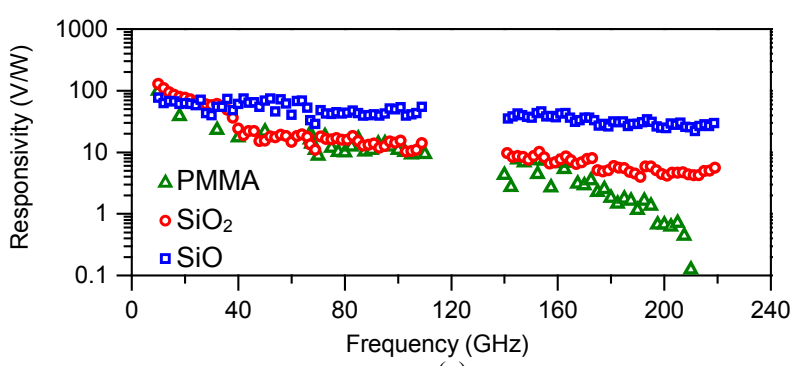

(a)

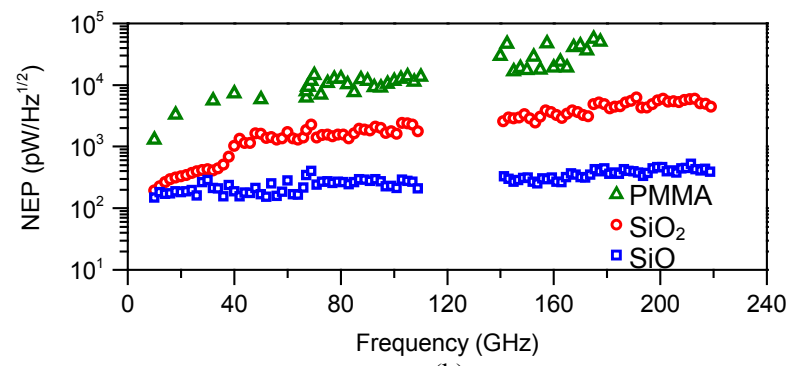

(b)

Fig. 6. Responsivity and NEP of SSDs fabricated with different masks. (a) Measured zero bias responsivity at room temperature. (b) Calculated thermal NEP with responsivity results.

the damaged depth in semiconductors after depositing $\mathrm{SiO}_{2}$ with RF sputtering could be as large as $150 \mathrm{~nm}$ [12]. The deposition-induced damage of sputtered $\mathrm{SiO}_{2}$ mask decreases the carrier density and mobility of devices, and, as a result, the

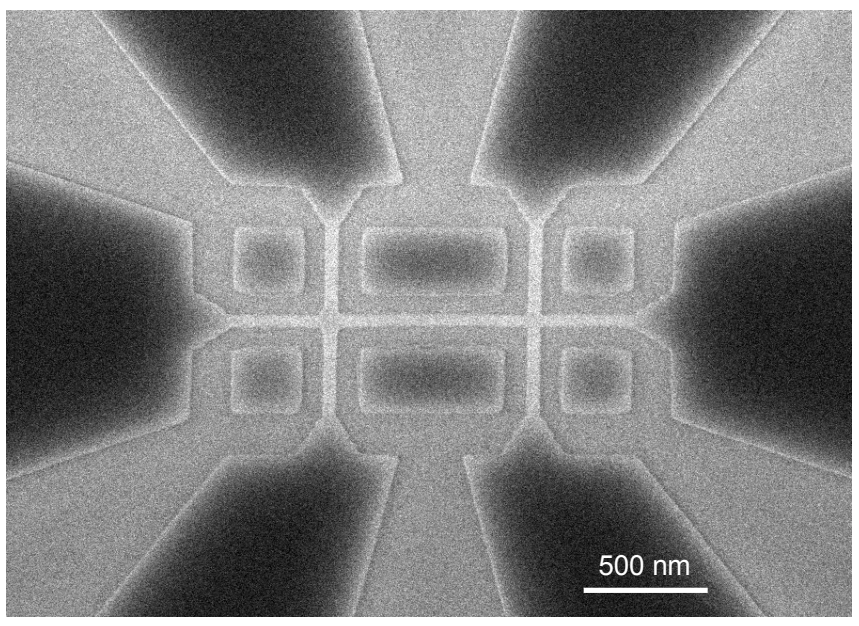

Fig. 7. SEM image of fabricated nanoscale Hall bar with SiO mask.

TABLE II

MEASURED CARRIER DENSITY AND HALL MOBILITY OF HALL BARS WITH $\mathrm{SIO}_{2}$ AND SIO MASK AT ROOM TEMPERATURE.

\begin{tabular}{ccccc}
\hline \hline $\begin{array}{c}\text { Channel width } \\
(\mathrm{nm})\end{array}$ & $\begin{array}{c}\mathrm{SiO}_{2} \text { mask } \\
\left(\times 10^{12} \mathrm{~cm}^{-2}\right)\end{array}$ & $\begin{array}{c}\mu \\
\mathrm{cm}^{2} / \mathrm{Vs}\end{array}$ & $\begin{array}{c}n \\
\left(\times 10^{12} \mathrm{~cm}^{-2}\right)\end{array}$ & $\begin{array}{c}\mu \\
\mathrm{cm}^{2} / \mathrm{Vs}\end{array}$ \\
\hline 100 & 1.72 & 465.37 & 2.23 & 1031.04 \\
125 & 1.62 & 473.55 & 2.28 & 1056.05 \\
150 & 1.62 & 515.95 & 2.06 & 1152.61 \\
200 & 1.66 & 484.06 & 2.40 & 1025.65 \\
\hline \hline
\end{tabular}

The magnetic field was $0.52 \mathrm{~T}$.

high frequency performance of the devices with $\mathrm{SiO}_{2}$ mask is 
influenced. Whereas, as the benefit of the damage-free thermal evaporated $\mathrm{SiO}$, the devices with $\mathrm{SiO}$ mask present much better performances.

\section{CONCLUSION}

A novel thermally evaporated dry etching mask material, $\mathrm{SiO}$, is developed. Its detailed characteristics have been performed and compared with the commonly used PMMA and $\mathrm{SiO}_{2}$ masks. The PMMA mask showed much less etching resistance than hard masks and, as a result, both the DC and high-frequency performance of the SSD fabricated with PMMA mask are very poor. Although the evaporated $\mathrm{SiO}$ and sputtered $\mathrm{SiO}_{2}$ masks showed similar etching resistance and produced nanoscale features with good morphology, the nanochannel conductance of the SSD with $\mathrm{SiO}$ mask is substantially higher than that with $\mathrm{SiO}_{2}$ mask. Hall measurements reveal that the carrier mobility of nanochannels etched with $\mathrm{SiO}$ mask is twice of the channels with $\mathrm{SiO}_{2}$ mask. Furthermore, at high-frequency characterizations of SSDs up to $220 \mathrm{GHz}$, the responsivity of the SSD with $\mathrm{SiO}$ mask was 6 times better than that with $\mathrm{SiO}_{2}$ mask. In conclusion, $\mathrm{SiO}$ is promising dry etching mask material because of its easy-deposition, high-performance and low-damage thermal evaporation process to the host materials.

\section{REFERENCES}

[1] K. J. Kuhn, "Considerations for Ultimate CMOS Scaling," IEEE Transactions on Electron Devices, vol. 59, no. 7, pp. 1813-1828, 2012.

[2] J. A. Alamo, "Nanometre-scale electronics with III-V compound semiconductors," Nature, vol. 479, no. 7373, pp. 317-23, Nov 17, 2011.

[3] X. Lu, C. Balocco, F. Yang, and A. M. Song, "Highly Reproducible Nanolithography by Dynamic Plough of an Atomic-Force Microscope Tip and Thermal-Annealing Treatment," IEEE Transactions on Nanotechnology, vol. 10, no. 1, pp. 53-58, 2011

[4] K. K. Lee, Y. Luo, X. F. Lu, P. Bao, and A. M. Song, "Development of Reactive-Ion Etching for ZnO-Based Nanodevices," IEEE Transactions on Nanotechnology, vol. 10, no. 4, pp. 839-843, Jul, 2011.

[5] Z. Xin, and J. A. del Alamo, "Nanometer-Scale Vertical-Sidewall Reactive Ion Etching of InGaAs for 3-D III-V MOSFETs," IEEE Electron Device Letters, vol. 35, no. 5, pp. 521-523, 2014.

[6] N. Haneji, G. Segami, T. Ide, T. Suzuki, T. Arakawa, K. Tada, Y. Shimogaki, and Y. Nakano, "Electron Cyclotron Resonance-Reactive Ion Etching of III-V Semiconductors by Cyclic Injection of CH4/H2/Ar and O2 with Constant Ar Flow," Japanese Journal of Applied Physics, vol. 42, no. Part 1, No. 6B, pp. 3958-3961, 2003.

[7] K.-m. Lim, S. Gupta, C. Ropp, and E. Waks, "Development of metal etch mask by single layer lift-off for silicon nitride photonic crystals," Microelectronic Engineering, vol. 88, no. 6, pp. 994-998, 2011.

[8] J. Zhang, M. Zhou, W. Wu, and Y. Tang, "Fabrication of Diamond Microstructures by Using Dry and Wet Etching Methods," Plasma Science and Technology, vol. 15, no. 6, pp. 552-554, 2013.

[9] J. S. Parker, E. J. Norberg, R. S. Guzzon, S. C. Nicholes, and L. A. Coldren, "High verticality InP/InGaAsP etching in $\mathrm{Cl}_{2} / \mathrm{H}_{2} / \mathrm{Ar}$ inductively coupled plasma for photonic integrated circuits," Journal of Vacuum Science \& Technology B, vol. 29, no. 1, pp. 011016, 2011.

[10] M. Lysevych, H. H. Tan, F. Karouta, and C. Jagadish, "Single-Step RIE Fabrication Process of Low Loss InP Waveguide Using $\mathrm{CH}_{4} / \mathrm{H}_{2}$ Chemistry," Journal of The Electrochemical Society, vol. 158, no. 3, pp. H281, 2011.

[11] M. K. Tripp, C. Stampfer, D. C. Miller, T. Helbling, C. F. Herrmann, C. Hierold, K. Gall, S. M. George, and V. M. Bright, "The mechanical properties of atomic layer deposited alumina for use in micro- and nano-electromechanical systems," Sensors and Actuators A: Physical, vol. 130-131, pp. 419-429, 2006.
[12] K. Tsubaki, S. Ando, K. Oe, and K. Sugiyama, "Surface Damage in InP Induced during $\mathrm{SiO}_{2}$ Deposition by rf Sputtering," Japanese Journal of Applied Physics, vol. 18, no. 6, pp. 1191-1192, 1979.

[13] J. F. Wager, "Plasma-enhanced chemical vapor deposited $\mathrm{SiO}_{2} / \mathrm{InP}$ interface," Journal of Applied Physics, vol. 53, no. 8, pp. 5789-5797, 1982.

[14] B. Sautreuil, P. Viktorovitch, and R. Blanchet, "Evidence for interfacial defects in metal-insulator-InP structures induced by the insulator deposition," Journal of Applied Physics, vol. 57, no. 6, pp. 2322-2324, 1985.

[15] K. Aoki, S.-i. Uekusa, and H. Katsumata, "Oxygen Plasma Damage in GaAs Directly Exposed to Surface-Wave Plasma," Japanese Journal of Applied Physics, vol. 41, no. Part 1, No. 9, pp. 5762-5768, 2002.

[16] A. M. Song, M. Missous, P. Omling, A. R. Peaker, L. Samuelson, and W. Seifert, "Unidirectional electron flow in a nanometer-scale semiconductor channel: A self-switching device," Applied Physics Letters, vol. 83, no. 9, pp. 1881-1883, 2003.

[17] A. M. Song, I. Maximov, M. Missous, and W. Seifert, "Diode-like characteristics of nanometer-scale semiconductor channels with a broken symmetry," Physica E: Low-dimensional Systems and Nanostructures, vol. 21, no. 2-4, pp. 1116-1120, 2004.

[18] S. R. Kasjoo, U. Hashim, and A. M. Song, "Fabrication of Nanodiodes Using Atomic-Force Microscope Lithography," 2013 IEEE Regional Symposium on Micro and Nanoelectronics (Rsm 2013), pp. 297-299, 2013.

[19] K. Schulmeister, and W. Mader, "TEM investigation on the structure of amorphous silicon monoxide," Journal of Non-Crystalline Solids, vol. 320, no. 1-3, pp. 143-150, 2003.

[20] J. R. Lothian, F. Ren, and S. J. Pearton, "Mask erosion during dry etching of deep features in III-V semiconductor structures," Semiconductor Science and Technology, vol. 7, no. 9, pp. 1199-1209, 1992.

[21] A. Westlund, "Novel Terahertz Emitters and Detectors InGaAs Slot Diodes and InAs Self-Switching Diodes," Department of Microtechnology and Nanoscience, Chalmers University of Technology, 2013

[22] C. Balocco, M. Halsall, N. Q. Vinh, and A. M. Song, "THz operation of asymmetric-nanochannel devices," Journal of Physics: Condensed Matter, vol. 20, no. 38, pp. 384203, Sep 24, 2008.

[23] C. Balocco, S. R. Kasjoo, L. Q. Zhang, Y. Alimi, and A. M. Song, "Low-frequency noise of unipolar nanorectifiers," Applied Physics Letters, vol. 99, no. 11, pp. 113511, 2011.

[24] S. R. Kasjoo, A. K. Singh, and A. M. Song, "RF characterization of unipolar nanorectifiers at zero bias," Physica Status Solidi (a), vol. 212, no. 9, pp. 2091-2097, 2015.

[25] K. Mitani, and T. Kawano, "Damage in a GaAs Surface Caused by RF-Sputter Deposition of SiO2," Japanese Journal of Applied Physics, vol. 34, no. Part 1, No. 9A, pp. 4649-4652, 1995. 